\title{
Total and Ionized Plasma Magnesium Concentrations in Children after Traumatic Brain Injury
}

\author{
DONNA REYES MENDEZ, RONALD CORBETT, CHARLES MACIAS, AND ABBOT LAPTOOK \\ Departments of Pediatrics [D.R.M.] and Pediatric Emergency Medicine [C.M.], Baylor College of \\ Medicine, Houston, TX 77030; Department of Radiology [R.C.], The University of Texas Southwestern \\ Medical Center, Dallas, TX 75390; and Department of Pediatrics/Neonatology [A.L.], The University of \\ Texas Southwestern Medical Center, Dallas, TX 75390
}

\begin{abstract}
This study examined 1 ) whether plasma total $\mathrm{Mg}(\mathrm{TMg})$ and ionized $\mathrm{Mg}(\mathrm{IMg})$ concentrations in children are reduced by traumatic brain injury (TBI) and 2) whether the extent of reduction correlates with severity of trauma assessed by the Glasgow Coma Scale (GSC) score. This was a prospective cohort study of 98 pediatric patients who had TBI and were admitted through the emergency department. A GCS score was assigned and blood was obtained upon presentation and $24 \mathrm{~h}$ later. Plasma was analyzed for $\mathrm{TMg}$ and $\mathrm{IMg}$. Patients were grouped into three categories-GCS scores 13-15, 8-12, and $<8$ - to designate mild $(n=21)$, moderate $(n=37)$, and severe $(n=40)$ TBI, respectively. Blood was obtained from 50 healthy children before elective surgery as controls. Control subjects had a TMg and an IMg of $0.94 \pm 0.08$ and $0.550 \pm 0.06 \mathrm{mM}$. TBI patients had an initial $\mathrm{TMg}$ and $\mathrm{IMg}$ of $0.83 \pm 0.09$ and $0.520 \pm 0.05 \mathrm{mM}$, respectively. Initial $\mathrm{TMg}$ for mild, moderate, and severe TBI subgroups $(0.87 \pm 0.16,0.81 \pm 0.15$, and $0.83 \pm 0.14 \mathrm{mM}$, respectively) was reduced from control subjects $(p<0.01)$. IMg
\end{abstract}

\section{ABSTRACT}

was reduced only in the severe TBI subgroup $(0.516 \pm 0.07 \mathrm{mM}$; $p=0.016)$. Twenty-four hours later, TMg remained lower than in control subjects for all subgroups of TBI; however, IMg normalized. TBI in children is associated with a reduction in $\mathrm{TMg}$, whereas IMg decreased only with severe TBI. IMg returned to control values by $24 \mathrm{~h}$ despite a continued lower $\mathrm{TMg}$, suggesting mechanisms to maintain IMg. Changes in plasma IMg may serve as a marker for TBI but only over a limited time interval. (Pediatr Res 57: 347-352, 2005)
CT, computed tomography
ED, emergency department
GCS, Glasgow Coma Scale
ICa, ionized calcium
IMg, ionized Mg
TBI, traumatic brain injury
TMg, total Mg

Traumatic brain injury (TBI) remains an important health problem in children. Hospitalizations are frequent after TBI (180/100,000 children) (1), mortality is substantial (10/100,000 children) (1), and up to 17,000 children per year are left with permanent developmental disabilities $(2,3)$. TBI represents the most common cause of acquired disability in childhood $(3,4)$. The pathogenesis of tissue injury after TBI remains complex, reflecting mechanical tissue destruction and multiple secondary processes such as energy failure, excitotoxin release, lipid peroxidation, osmodysregulation, apoptosis, and other pathways (5-8). Over the past $15 \mathrm{y}$, there has been growing interest

Received February 26, 2004; accepted August 2, 2004.

Correspondence: Donna Mendez, M.D., 6211 Fannin Street, Room A210, Baylor College of Medicine, Department of Pediatric Emergency Medicine, Houston, TX 77030; e-mail: drmendez@texaschildrenshospital.org

Supported by the Texas Advanced Research Technology Program, Grant No. 003660068, and NOVA Biomedical Corp., Waltham, MA.

DOI: 10.1203/01.PDR.0000150803.36315.FF in altered $\mathrm{Mg}$ homeostasis after TBI and a potential neuroprotective role for exogenous $\mathrm{Mg}$ administration. The proposed link between TBI and $\mathrm{Mg}$ is based primarily on work in an experimental model of TBI in rodents in which a fluid percussion model was used to induce damage. In this TBI model, both brain total and intracellular Mg (measured with P-31 magnetic resonance spectroscopy) (9-11) were reduced, and the extent of injury correlated with the decrease in total and intracellular Mg (12). Supplemental parenteral Mg administered as prophylaxis minimized the decrease in brain $\mathrm{Mg}$ and improved neurobehavioral scores (12-15). In addition, $\mathrm{Mg}$ that was given to rodents that sustained TBI attenuated histologic brain damage (16).

Instruments to measure ionized $\mathrm{Mg}$ ( $\mathrm{IMg}$ ) using ionselective electrodes are now commercially available. This has prompted studies in adult rodents to determine whether $\mathrm{Mg}$ concentrations (either total or ionized) are altered after TBI in body fluids, such as blood or plasma, that are more readily 
available than brain tissue. In one study, total blood $\mathrm{Mg}$ was unchanged but IMg was reduced. Supplemental Mg administered $1 \mathrm{~h}$ after TBI corrected the lower IMg (12). More important, there was a direct relationship between IMg immediately after TBI and motor function at 1-2 wk after the injury (12). This work has been extended to human adults $(17,18)$. In these two reports, TBI was associated with either no change (17) or a reduction in total $\mathrm{Mg}(\mathrm{TMg})$ in the blood (18), but both report a decrease in IMg. At present, no studies have delineated the changes in blood $\mathrm{Mg}$ concentration after TBI in an exclusively pediatric population. As an initial step in examining alterations in $\mathrm{Mg}$ concentrations after TBI, this investigation had the following two objectives: 1 ) to determine whether plasma TMg or IMg concentrations decrease in children after TBI and 2) to determine whether plasma $\mathrm{TMg}$ or $\mathrm{IMg}$ concentrations change as a function of the severity of TBI.

\section{METHODS}

This study was approved by the Institutional Review Board of the University of Texas Southwestern Medical Center, and informed consent was obtained on all study patients. This was a prospective cohort study initiated in January 1998 and completed in May 1999.

Study setting and group. The study subjects consisted of 98 children who had TBI and presented to a level I pediatric trauma emergency department (ED) of Children's Medical Center of Dallas, an affiliate of Southwestern Medical Center. Inclusion criteria were history of a head injury, $<18 \mathrm{y}$ of age, assessment with a head computed tomography (CT) scan within the first $5 \mathrm{~h}$ of injury, and admission to the pediatric intensive care unit. Any patient with a GCS score $<14$ or positive head CT findings was routinely admitted to the pediatric intensive care unit in our institution. Fifty healthy children who were to have elective surgery during January 1998 to May 1999 served as a comparison group. Blood was drawn in the operating room before surgery or anesthesia, at the time an i.v. line was placed. Exclusion criteria for either group were medical conditions or medications that could alter Mg levels, such as renal disease, endocrine disorders, aminoglycosides, diuretics, and digitalis. All patients with TBI were evaluated using the Glasgow Coma Scale (GCS) (19) to assess the severity of TBI initially on presentation to the ED and again at $24 \mathrm{~h}$ after initial assessment. Scoring for the GCS was performed by the same investigator for all patients with TBI.

Study protocol and measurements. Blood was drawn on presentation to the ED (day 1) and $\sim 24 \mathrm{~h}$ later (day 2). Blood was drawn under anaerobic conditions and placed into 3-mL glass green-top Vacutainer tubes (Becton Dickinson, Franklin Lakes, NJ) that contained 15 units of sodium heparin $/ \mathrm{mL}$ of blood. Previous studies have shown that this concentration of heparin does not affect the concentration of IMg in plasma (20). The samples were immediately centrifuged at $3000 \mathrm{rpm}$ and stored at $4^{\circ} \mathrm{C}$ for $<24 \mathrm{~h}$ and then at $-75^{\circ} \mathrm{C}$ until their analysis within 4 mo of sampling. Freezing and thawing has been previously shown not to alter IMg concentrations (21). IMg concentration was measured using the NOVA 8 ISE Analyzer (NOVA Biomedical, Waltham, MA). This instrument was also used to measure concurrently sample $\mathrm{pH}$, ionized calcium $(\mathrm{ICa})$, sodium $(\mathrm{Na})$, and potassium $(\mathrm{K})$ concentrations. All measurements were made at $37^{\circ} \mathrm{C}$ using $200 \mu \mathrm{L}$ of plasma. IMg and $\mathrm{ICa}$ are reported after correcting for sample $\mathrm{pH}$ and were normalized to a $\mathrm{pH}$ of 7.4. The instrument was calibrated using the manufacturer's standards, and the electrodes for $\mathrm{Mg}$ and $\mathrm{Ca}$ were replaced at intervals specified by the manufacturer. TMg concentration was determined in duplicate using a Varian SpectraAA Atomic Absorption Spectrophotometer (Varian Optical Spectroscopy Instruments, Mulgrave, Australia) equipped with an air-acetylene flame, and detector was set at $285.2 \mathrm{~nm}$. Plasma samples were diluted 250 times (10 $\mu \mathrm{L}$ in $2.5 \mathrm{~mL}$ ) into a solution that contained $0.5 \%$ lanthanum oxide to minimize chemical interference as recommended by the manufacturer. The instrument was calibrated using commercial Mg standards (Sigma Chemical Co., St. Louis, MO).

Data analysis. Children with TBI were classified into three groups according to the severity of injury on presentation using the GCS score. Mild TBI was defined as a GCS score of 13-15, moderate TBI was defined as a GCS score of $8-12$, and severe TBI was defined as a GCS score of $<8$. Group data are expressed as a mean $\pm \mathrm{SD}$, and continuous data were analyzed using $t$ test and ANOVA for continuous variables. Descriptive categorical results were analyzed using $\chi^{2}$ analysis. A $p<0.05$ was considered significant. Statistical analysis was done utilizing Excel and Mini-tab.

\section{RESULTS}

A total of 98 children with TBI were studied. Children with TBI were $6.3 \pm 6 \mathrm{y}$ of age. The average age of children in the three TBI subgroups was the same (Table 1). Children in the control group were similar in age $(5.8 \pm 3.8 \mathrm{y})$. The time from injury to the time that the first blood sample was drawn was similar in all three TBI groups. Sex and ethnicity were similar in the control group and the TBI group ( $p=0.4$ and $p=0.6$, respectively). The major causes of TBI included motor vehicle accidents (46\%), motor pedestrian collisions (28\%), and falls $(21 \%)$. Selected clinical characteristics of children who were classified as having mild, moderate, and severe TBI are presented in Table 1. As expected, fewer children who were classified as having mild TBI required intubation or pressor support, compared with children who were classified as having moderate and severe TBI. Likewise, intracranial pressure monitoring was not required in children in the mild TBI group but was required in 10 and $45 \%$ of children in the moderate and severe TBI groups. In contrast, similar numbers of abnormalities on CT scans (subdural, subarachnoid, and epidural hemorrhage; contusion; and edema) were observed in all three groups $(86 \%$ of mild, $68 \%$ of moderate, and $57 \%$ of children with severe TBI). Magnetic resonance imaging was not performed in all patients, which would have identified patients with diffuse axonal injury that is associated with more severe TBI.

The TMg and IMg concentrations for the control group were $0.94 \pm 0.08$ and $0.550 \pm 0.06$, respectively (Table 2 ). There was no correlation between either TMg or IMg concentration and age for the control group ( $p>0.05$ for both). On day 1 , the TBI group as a whole had lower average $\mathrm{TMg}$ and $\mathrm{IMg}$ concentrations $(0.83 \pm 0.09$ and $0.523 \pm 0.05 \mathrm{mM}$, respectively) compared with the control group ( $p \leq 0.01$ and $p=$ 0.036 , respectively, for $\mathrm{TMg}$ and $\mathrm{IMg}$ ). Moreover, a significant reduction in $\mathrm{TMg}$ was found in each $\mathrm{TBI}$ subgroup. $\mathrm{IMg}$ concentration, however, was the same as the control group for mild $(0.540 \pm 0.07 \mathrm{mM} ; p=0.6)$ and moderate TBI $(0.518 \pm$

Table 1. Characteristics and treatment in first 48 hours

\begin{tabular}{lcccccrc}
\hline \multicolumn{1}{c}{ GCS } & $n$ & Age $(\mathrm{y})$ & $\begin{array}{c}\text { Time }(\mathrm{h}) \\
\text { Injury-ED }\end{array}$ & $\begin{array}{c}\text { Intubated } \\
(\%)\end{array}$ & $\begin{array}{c}\text { Pressor support } \\
(\%)\end{array}$ & $\begin{array}{c}\text { ICP monitoring } \\
(\%)\end{array}$ & $\begin{array}{c}\text { Abnormal CT } \\
(\%)\end{array}$ \\
\hline $13-15$ & 21 & $7.3 \pm 3.4$ & $3.7 \pm 2.1$ & 24 & 0 & 0 & 86 \\
$8-12$ & 37 & $6.0 \pm 3.7$ & $3.9 \pm 6.5$ & 43 & 3 & 10 & 68 \\
$<8$ & 40 & $6.2 \pm 3.5$ & $4.2 \pm 3.4$ & 90 & 20 & 45 & 57 \\
Control & 50 & $5.8 \pm 3.8$ & & & & \\
\hline
\end{tabular}

Intubation, pressor support, and ICP monitoring refer to any time in the first $48 \mathrm{~h}$ of hospitalization. 
Table 2. TMg and IMg levels

\begin{tabular}{|c|c|c|c|c|}
\hline & \multicolumn{2}{|c|}{ Day 1} & \multicolumn{2}{|c|}{ Day 2} \\
\hline & $\mathrm{TMg}$ & $\mathrm{IMg}$ & $\mathrm{TMg}$ & $\mathrm{IMg}$ \\
\hline Control $(n=50)$ & $0.94 \pm 0.08$ & $0.550 \pm 0.06$ & - & - \\
\hline Total TBI $(n=98)$ & $0.83 \pm 0.09$ & $0.523 \pm 0.08$ & $0.86 \pm 0.09$ & $0.571 \pm 0.07$ \\
\hline GCS $13-15(n=21)$ & $0.87 \pm 0.16^{*}$ & $0.540 \pm 0.07$ & $0.90 \pm 0.09$ & $0.610 \pm 0.07 \ddagger$ \\
\hline GCS $8-12(n=37)$ & $0.81 \pm 0.15^{*}$ & $0.518 \pm 0.10$ & $0.86 \pm 0.09 \ddagger$ & $0.570 \pm 0.08 \S$ \\
\hline GCS $<8(n=40)$ & $0.83 \pm 0.14^{*}$ & $0.516 \pm 0.07 \dagger$ & $0.84 \pm 0.11 \neq$ & $0.560 \pm 0.08^{\S}$ \\
\hline
\end{tabular}

All values are $\mathrm{mM}$.

$* p \leq 0.01$.

$\dagger p=0.016$ vs control.

$\ddagger p \leq 0.01$ vs control.

$\S p \leq 0.015$ for day 1 vs day 2 .

$0.10 \mathrm{mM} ; p=0.06)$ but was reduced for severe TBI $(0.516 \pm$ $0.07 \mathrm{mM} ; p=0.016$; Table 2).

On day 2, all children who were classified as having mild TBI, with an initial GCS of 13-15, had the same score. For children with moderate TBI, an initial GCS of $8-12,3 \%$ had the same GCS score, $75 \%$ improved with a GCS score of $13-15$, and $15 \%$ deteriorated with a score $<8$ on day 2 . For children with severe TBI, with an initial GCS of $<8,55 \%$ had the same score and $45 \%$ had an improved score on day 2 . For both the moderate and the severe TBI groups with an improved GCS score, TMg did not improve $(p=0.178, p=1.01)$. Likewise, the IMg level did not improve $(p=0.189, p=1.01)$. The TMg concentration for the moderate and severe TBI subgroups remained reduced versus the control (Table 2). Although the TMg remained low in all TBI subgroups compared with the control, the TBI patients did show an increase in TMg levels between day 1 and day 2 of the study. On day 2, IMg concentration in each of the three TBI subgroups did not differ compared with control values. IMg concentration on day 2 increased compared with day 1 for moderate and severe subgroups of TBI ( $p \leq 0.015$; Table 2$)$. The same direction of effect was present for IMg in the mild TBI subgroup. For the severe TBI subgroup, IMg on day 2 was similar in children with a GCS score that remained $<8(0.57 \pm 0.08 \mathrm{mM} ; n=$ 13 ), compared with children in whom the GCS improved to $\geq 8$ $(0.55 \pm 0.07 \mathrm{mM} ; n=21)$.

In the patient population studied, $33 \%$ of patients had an associated non-CNS traumatic injury $(n=1$ mild TBI, $n=12$ moderate TBI, $n=20$ severe TBI). Sixty-six percent $(n=20$ for mild TBI, $n=25$ for moderate TBI, and $n=20$ for severe TBI) had isolated head injuries. Non-CNS trauma included bone fractures and splenic, liver, pulmonary, renal, and cardiac injuries. The isolated head-injured patients had similar $\mathrm{TMg}$ and $\mathrm{IMg}$ levels on presentation and $24 \mathrm{~h}$ later when compared with the entire TBI group (Table 3).
Plasma Na concentration was similar in the control group and each subgroup of TBI on presentation and $24 \mathrm{~h}$ after the head injury (Table 4). Plasma $\mathrm{K}$ concentration on day 1 , however, was lower in each subgroup of TBI compared with the control group but increased to levels similar to control values in the mild and moderate TBI subgroups on day 2. ICa concentration for all three TBI subgroups on day 1 were lower than in the control group. By day 2, ICa had returned to control values in each TBI subgroup.

\section{DISCUSSION}

This investigation has characterized the changes in $\mathrm{TMg}$ and $\mathrm{IMg}$ concentration that occur within $5 \mathrm{~h}$ after TBI and $24 \mathrm{~h}$ after TBI in children who are deemed sufficiently ill enough to warrant hospitalization to a pediatric intensive care unit. The principal findings of this study included the following: 1) a 0.07 - to $0.14-\mathrm{mM}$ reduction in $\mathrm{TMg}$ concentration upon presentation to the ED, which occurred in all severities of head injury; 2) a relatively smaller, 0.01 to $0.03 \mathrm{mM}$, reduction in IMg concentration during this same period, which was significant only for children with the most severe TBI as indicated by their GCS score; 3) persistence of the reduction in $\mathrm{TMg}$ concentration $24 \mathrm{~h}$ after TBI; and 4) resolution of the reduced $\mathrm{IMg}$ concentration during this later period. The changes in $\mathrm{TMg}$ and $\mathrm{IMg}$ in children with isolated TBI were nearly identical to the changes in $\mathrm{Mg}$ for the entire study group of TBI. This suggests that TBI alone and not a general response to trauma accounts for the changes observed in $\mathrm{Mg}$.

The most prominent finding of this study was the lower $\mathrm{TMg}$ concentration for children with TBI compared with control subjects. Because of the suggestion that alterations in brain tissue MG may play an important role in the pathogenesis of tissue injury $(13,14,22)$, several studies have tried to address whether changes in the brain are mirrored by similar changes

Table 3. Isolated head injury

\begin{tabular}{|c|c|c|c|c|}
\hline & \multicolumn{2}{|c|}{ Day 1} & \multicolumn{2}{|c|}{ Day 2} \\
\hline Total TBI & $0.83 \pm 0.14$ & $0.523 \pm 0.08$ & $0.86 \pm 0.09$ & $0.571 \pm 0.07$ \\
\hline$p$ values & 0.835 & 0.972 & 0.605 & 0.265 \\
\hline
\end{tabular}


Table 4. Plasma electrolytes

\begin{tabular}{|c|c|c|c|c|c|c|}
\hline & \multicolumn{3}{|c|}{ Day 1} & \multicolumn{3}{|c|}{ Day 2} \\
\hline & $\mathrm{ICa}$ & $\mathrm{Na}$ & $\mathrm{K}$ & $\mathrm{ICa}$ & $\mathrm{Na}$ & $\mathrm{K}$ \\
\hline Control $(n=50)$ & $1.19 \pm 0.06$ & $139 \pm 6$ & $4.4 \pm 0.9$ & - & - & - \\
\hline \multicolumn{7}{|l|}{ TBI $(n=98)$} \\
\hline GCS 13-15 & $1.13 \pm 0.10^{*}$ & $139 \pm 3$ & $3.8 \pm 0.8 *$ & $1.19 \pm 0.10$ & $140 \pm 5$ & $4.4 \pm 0.7$ \\
\hline GCS 8-12 & $1.15 \pm 0.14^{*}$ & $139 \pm 4$ & $3.9 \pm 1.0 *$ & $1.21 \pm 0.12$ & $138 \pm 5$ & $4.1 \pm 0.6$ \\
\hline $\mathrm{GCS}<8$ & $1.10 \pm 0.10^{*}$ & $140 \pm 5$ & $3.6 \pm 0.7^{*}$ & $1.19 \pm 0.09 \dagger$ & $137 \pm 9$ & $3.8 \pm 0.5$ \\
\hline
\end{tabular}

$* p \leq 0.01$ for control $v s$ day 1 .

$\dagger p \leq 0.01$ for day $1 v s$ day 2 .

in the blood. Although there are limited data, animals have been used for this purpose because standardized TBI models have been created. In adult rats, a fluid percussion brain injury has been used to demonstrate that blood $\mathrm{Mg}$ concentration does not change over a 24-h period after injury (12). These observations are in contrast to human adults with TBI. King et al. (23) reported lower TMg in five of seven adults with TBI on the day of the event. Similarly, Cernak et al. (18) compared 31 male adults with TBI with 10 age-matched male adults. His control subjects had a total plasma $\mathrm{Mg}$ concentration (0.96 \pm $0.02 \mathrm{mM}$ ), similar to our control subjects. TBI was associated with a significant reduction in $\mathrm{TMg}$ concentration for all patients with average values between 0.72 and $0.81 \mathrm{mM}$ depending on the severity of injury. Similar to our observation in children, the reduction in $\mathrm{TMg}$ concentration persisted, remaining low for $2 \mathrm{~d}(\mathrm{GCS}=13-15)$ or for $3 \mathrm{~d}(\mathrm{GCS}=4-6)$. Memon et al. (17) studied 66 predominantly adults (age range 13-82 y) with TBI and compared with the TMg concentration to values in healthy adults $(0.81 \pm 0.01 \mathrm{mM})$ and other patients without TBI but with minor injuries $(0.85 \pm 0.01 \mathrm{mM})$. Values for patients with TBI were not different compared with the two control groups. However, his results suggested a trend toward lower $\mathrm{TMg}$ concentration was suggested with increasing severity of TBI (i.e. $0.82 \pm 0.02,0.79 \pm 0.02$, and $0.73 \pm 0.04$ for GCS for 15, 10-14, and $<10$, respectively), and the lack of differences may reflect the sample size $(n=9,52$, and 6, respectively, for the designated GCS).

There are a several theories to explain a reduction in plasma TMg after TBI. For example, free water retention as a result of the syndrome of inappropriate secretion of antidiuretic hormone after TBI (24) could incidentally reduce the blood TMg concentration. This possibility, however, is not supported by a serum Na concentration of the TBI group, which did not differ on day 1 compared with the controls. Alternatively, the reduction in total plasma $\mathrm{Mg}$ after TBI may reflect enhanced renal excretion of Mg. The rapid reduction in plasma $\mathrm{TMg}$ within hours of the injury would make renal losses of $\mathrm{Mg}$ very unlikely. This is also suggested by reports that patterns of urinary excretion of $\mathrm{Mg}$ in adult humans with head trauma are not increased shortly after injury (23). We are unaware of analogous data collected for children with TBI. Another alternative is suggested by data obtained from adults indicating strong adrenergic control of plasma Mg. Specifically, infusions of adrenaline in healthy adult humans resulted in a 10-15\% reduction in plasma TMg concentration (25-27). Experiments performed on adult ewes demonstrated that the adrenaline induced by hypomagnesemia was abolished by $\beta$-adrenoreceptor blockade with propranolol (28). Hormonal mediators have been quantified in children with severe TBI (GCS score $<8$ ), and circulating adrenaline levels were found to be markedly elevated (29).

Altura et al. (30) showed that low levels of $\mathrm{TMg}$ are associated with a number of pathophysiologic states such as cardiovascular disease (congestive heart failure, myocardial ischemic syndrome, acute myocardial infarction, and hypertension) and diabetes. The relationship between a lowered $\mathrm{TMg}$ and these pathophysiologic states has been investigated. Experiments using diabetic rats suggest that their altered vascular tone may be due to a modification of the $\mathrm{Mg}$-Ca exchange sites at their vascular smooth muscle membrane. In reference to cardiovascular disease, Altura et al. (31) showed in an animal model that blood vessels, especially arteries and arterioles deficient in $\mathrm{Mg}$, can undergo constriction and spasm; the greater the reduction in $\mathrm{Mg}$, the greater the magnitude of contraction in an animal model. Altura hypothesized that selfinduced stress with the accompanying catecholamine secretion as seen in type A behavior increases lipolysis. This increase in lipolysis increases blood FFA, which leads to a TMg deficiency, which ultimately leads to cardiovascular disease (32).

Low plasma $\mathrm{Mg}$ concentration can be a consequence of medications or medical conditions; chelation by citrated blood products; and redistribution into cells by glucose infusions, amino acid infusions, or catecholamine infusions. Patients were not included when they had a medical condition or took medications that could potentially alter their plasma $\mathrm{Mg}$. In addition, patients in this study had their initial $\mathrm{Mg}$ drawn before blood products or medications were given, and none of the low levels of MG were treated because the levels were analyzed at least 1 wk after collection. No patient was given Mg during the study.

A final pathway that could contribute to the reduction in plasma TMg concentration involves alterations in lipid metabolism. At a cellular level, TBI can be associated with peroxidative membrane damage (33), similar to that observed for traumatic spinal cord injury (34). Consistent with enhanced lipid peroxidation is the increase in brain phospholipase activity shortly after TBI (35). Hydrolysis of the cellular membrane may result in loss of lipid and associated bound MG, thereby contributing to reduced brain tissue $\mathrm{TMg}$. Consistent with this concept is in vitro data obtained with ${ }^{31} \mathrm{P}$ magnetic resonance spectroscopy to measure free $\mathrm{Mg}$ concentration, which demonstrated that enzymatic hydrolysis of artificial membrane 
vesicles by phospholipase $\mathrm{C}$ reduced the free $\mathrm{Mg}$ concentration (36). These results suggested that alteration in membrane phospholipid metabolism may change $\mathrm{Mg}$ binding with consequent alterations in the IMg concentration. In adults with TBI, parallel changes in oxidative stress have been demonstrated in the blood, as indicated by elevated lipid peroxidation products and superoxide anions, with a parallel fall in plasma TMg concentration (18). Given that catecholamines may be an important source of reactive oxygen species, there may be a close interrelationship between the sympathetic response to TBI and oxidative injury.

Results of the present study show that although there are prominent changes in the $\mathrm{TMg}$ concentration in blood after TBI, these alterations occurred irrespective of the severity of head injury initially. In contrast, children with severe TBI in the current study had only a small, $0.03-\mathrm{mM}$, reduction in $\mathrm{IMg}$ concentrations, but this was significant. Those with mild or moderate injury had no reduction. IMg in the moderate subgroup trended toward a significant reduction $(p=0.06)$ and may reflect an issue of sample size. These observations are not consistent with previous observations in either adult humans or adult animal models of TBI.

Measurement of blood IMg measurements in adult humans after TBI have strong parallels to the above rodent studies. Memon et al. (17) reported reductions in serum IMg concentrations for 66 adults with acute blunt head trauma, with the extent of the decrease in $\mathrm{Mg}$ paralleling the severity of injury (e.g. $<10 \%$ decrease for mild injury, $25 \%$ decrease for severe injury). Cernak et al. (18) reported that plasma $\mathrm{IMg}$ was reduced after either mild or severe head injury (GCS 13-15 and $4-6$, respectively) and remained decreased for a longer interval in the more severe (37).

In contrast, the present study reveals that the initial plasma $\mathrm{IMg}$ concentration was only slightly reduced for the subgroup with the most severe head injury. The magnitude of the decrease was $<10 \%$ compared with age-matched control subjects $(0.516 \pm 0.07$ versus $0.55 \pm 0.06 \mathrm{mM}$, respectively), with a similar direction of effect found for children who were classified as having moderate TBI (GCS $=8-12, \mathrm{IMg}=0.518 \pm$ $0.10 ; p=0.06$ ). Even though these changes in IMg were small, they were significant for the severely injured. Measurement of blood IMg in children has been scarcely studied, with $\mathrm{IMg}$ never being measured in children with TBI. IMg in healthy children has been reported as a narrow range between 0.56 and $0.62 \mathrm{mM}$ using the same measuring apparatus as we used (38). Another important difference between the results for children and adult humans/rodents is the transient changes of $\mathrm{IMg}$ concentration in children after TBI. For example, for the subgroup of children with severe TBI (GCS $<8$ ), IMg concentration had increased to $0.56 \pm 0.08 \mathrm{mM}$ by $24 \mathrm{~h}$ after injury, which was similar to control patients. In addition, IMg concentration increased between presentation and the 24-h sample for the moderate TBI group (GCS $=8-12,0.518 \pm 0.10$ to $0.57 \pm 0.08 \mathrm{mM} ; p=0.013$ ), with the same trend for mild TBI $(\mathrm{GCS}=13-15,0.54 \pm 0.07$ to $0.61 \pm .07 \mathrm{mM} ; p=0.06)$. These observations suggest that there are mechanisms to increase IMg concentrations despite a persisting low total blood $\mathrm{Mg}$ concentration. There are different pools of $\mathrm{Mg}$ in plasma, including $\mathrm{Mg}$ bound to low-affinity, low-molecular-weight ligands (e.g. phosphate, bicarbonate, lactate), high-affinity, highmolecular-weight ligands (proteins), and free $\mathrm{Mg}$ or $\mathrm{IMg}$ $(20,39)$. Because IMg is the physiologically active form and is responsible for multiple critical roles in cellular metabolism (enzyme co-factor, protein regulator), mechanisms to shift $\mathrm{Mg}$ from low-affinity bound sites to the free pool would seem plausible.

Studies that examined changes in $\mathrm{TMg}$ and $\mathrm{IMg}$ concentration in blood after TBI have done so in the hope that brain tissue changes will be reflected in the blood, as a consequence either of the tissue changes or of similar events that affect red cells. If this could be demonstrated in humans as has been done in rodents, then $\mathrm{IMg}$ concentration in the blood may be a marker for brain tissue injury in humans, with possible prognostic, diagnostic, or even therapeutic implications. The results of the present investigation in children suggest that the usefulness of IMg measurements in the blood may be limited to a short interval after severe TBI. This is supported by the increase in IMg concentration in children with severe TBI to levels similar to control children by $24 \mathrm{~h}$ after the injury. In addition, there was no difference in the $\mathrm{IMg}$ concentration among children who had severe TBI on admission and either improved or did not improve their GCS scores by $24 \mathrm{~h}$ after the injury. The present results are limited, however, by the absence of long-term neurodevelopmental follow-up for these children. A more extensive study with more frequent blood Mg sampling in the first $24 \mathrm{~h}$ after TBI and long-term follow-up would be worthwhile. Much more data are required before $\mathrm{Mg}$ can be considered a treatment for TBI.

\section{CONCLUSIONS}

TBI in children is associated with a reduction in $\mathrm{TMg}$, whereas IMg decreased only with severe TBI. IMg returned to control values by $24 \mathrm{~h}$ despite a continued lower $\mathrm{TMg}$, suggesting mechanisms to maintain IMg. Changes in plasma IMg may serve as a marker for TBI but only over a limited interval.

\section{REFERENCES}

1. Michaud LJ, Duhaime AC, Batshaw ML 1993 Traumatic brain injury in children Pediatr Clin North Am 40:553-565

2. Kraus JF 1995 Epidemiological features of brain injury in children: Occurrence, children at risk, causes and manner of injury, severity, and outcomes. In: Broman SH, Michel ME (eds) Traumatic Head Injury in Children. Oxford University Press, New York, pp 23-29

3. Kraus JF, Fife D, Conroy C 1987 Pediatric brain injuries: the nature clinical course, and deadly outcomes in a defined United States population. Pediatrics 79:501-507

4. Kraus JF, Rock A, Hemyari P 1990 Brain injuries among infants, children, adolescents, and young adults. Am J Dis Child 144:684-691

5. Yang MS, DeWitt DS, Becker DP, Hayes RL 1985 Regional brain metabolite levels following mild experimental head injury in the cat. J Neurosurg 63:617-621

6. Siesjo BK, Weilock T 1985 Central Nervous System Status Report. William Byrd Press, Richmond, pp 513-532

7. Tyurin VA, Tyurina YY, Burisenko GC, Sokolov TV, Ritov VB, Quinn PJ, Rose M, Kochanek P, Graham SM, Kagan VE 2000 Oxidative stress following traumatic brain injury in rats: quantitation of biomarkers and detection of free radical intermediate. J Neurochem 75:2178-2189

8. Ng I, Tseng-Tsai Y, Tank W, Soong R, Ng PY, Smith DR 2000 Apoptosis occurs after cerebral contusions in humans. Neurosurgery 46:949-956

9. Heath DL, Vink R 1998 Neuroprotective effects of $\mathrm{MgSO}_{4}$ and $\mathrm{MgCl}_{2}$ in closed head injury: a comparative phosphorous NMR study. J Neurotrauma 3:183-189

10. Heath DL, Vink R 1997 Traumatic brain axonal injury produces sustained decline in intracellular free magnesium concentration. Brain Res 38:150-153 
11. Vink R, McIntosh T, Demediuk P, Faden AI 1987 Decrease in total and free magnesium concentration following TBI in rats. Biochem Biophys Res Commun 142:594-599

12. Bareyre FM, Saatman KE, Helfaer MA, Sinson G, Wiesser JD, Brown Al, McIntosh TK 1999 Alterations in ionized and total blood magnesium after experimental traumatic brain injury: relationship to neurobehavioral outcome and neuroprotective efficacy of magnesium chloride. J Neurochem 73:271-280

13. Feldman Z, Gurevitch B, Artru AA, Oppenheim A, Shohami E, Reichenthal E, Shapira Y 1996 Effect of magnesium given 1 hour after head trauma on brain edema and neurological outcome. J Neurosurg 85:131-137

14. McIntosh TK, Vink R, Yamakami I, Fader AI 1989 Magnesium protects against neurological deficit after brain injury. Brain Res 482:252-260

15. Hoane MR, Irish SL, Marks BB, Barth TM 1998 Preoperative regimens of magnesium facilitate recovery of function and prevent subcortical atrophy following lesions of the rat sensorimotor cortex. Brain Res Bull 45:45-57

16. Bareyre FM, Saatman KE, Raghupathi R, McIntosh TK 2000 Postinjury treatmen with magnesium chloride attenuates cortical damage after traumatic brain injury in rats. J Neurotrauma 17:1029-1039

17. Memon ZI, Altura BT, Benjamin JL, Cracco RQ, Altura BM 1995 Predictive value of serum ionized but not total magnesium levels in head injuries. Scand J Clin Lab Invest 55:671-677

18. Cernak I, Savic VJ, Kotur J, Prokic V, Veljovic M, Grbovic D 2000 Characterization of plasma magnesium concentration and oxidative stress following graded traumatic brain injury in humans. J Neurotrauma 17:53-68

19. Dolan M 1997 Head Trauma. In: Barkin Roger M (ed) Pediatric Emergency Medicine: Concepts and Clinical Practice. Mosby, St. Louis, pp 243-245

20. Altura BT, Shirey TL, Young CC, Hiti J, Dell'Orfano K, Handwerker SM, Altura BM 1992 A new method for the rapid determination of ionized $\mathrm{Mg} 2+$ in whole blood, serum and plasma. Methods Find Exp Clin Pharmacol 14:297-304

21. Corbett R, Batista A, Laptook A, Sherry AD 1999 A macrocylic reporter ligand for $\mathrm{Mg} 2+$ : analytic implications for clinical magnesium determinations. Magnes Res $12: 79-88$

22. Vink R, McIntosh TK 1990 Pharmacological and physiological effects of magnesium on experimental traumatic brain injury. Magnes Res 3:163-169

23. King LR, Knowles HC Jr, Mclaurin RL 1973 Calcium, phosphorus, and magnesium metabolism following head injury. Ann Surg 77:126-131

24. McLaurin RL, King LR 1976 Handbook of Clinical Neurology. North-Holland Publishing Co., Amsterdam, pp 109-128
25. Ryzen E, Servis KL, Rude RK 1990 Effect of intravenous epinephrine on serum magnesium and free intracellular red blood cell magnesium concentrations measured by nuclear magnetic resonance. J Am Coll Nutr 9:114-119

26. Whyte KF, Addis GJ, Whitesmith R, Reid JL 1987 Adrenergic control of plasma magnesium in man. Clin Sci 72:135-138

27. Joborn H, Akerstrom G, Ljunghall S 1985 Effects of exogenous catecholamines and exercise on plasma magnesium concentrations. Clin Endocrinol 23:219-226

28. Rayssiguier Y 1997 Hypomagnesemia resulting from adrenaline infusions in ewes: its relation to lipolysis. Horm Metab Res 9:309-314

29. Matthews DS, Aynsley-Green A, Matthews JN, Bullock RE, Cooper BG, Eyre JA 1995 The effect of severe head injury on whole body energy expenditure and its possible hormonal mediators in children. Pediatr Res 37:409-417

30. Altura BM, Carella A, Altura BT 1980 Magnesium ions control prostaglandin reactivity of venous smooth muscle from spontaneously hypertensive rats. Prostaglandins Med 4:255-262

31. Altura BM, Altura BT 1984 Microcirculatory actions and uses of naturally-occurring (magnesium) and novel synthetic calcium channel blockers. Microcirc Endothelium Lymphatics 1:185-220

32. Altura BT 1980 Type-A behavior and coronary vasospasm: a possible role of hypomagnesemia. Med Hypotheses 6:753-757

33. Demediuk P, Faden AI, Romhanyi R, Vink R, McIntosh TK 1988 Traumatic brain injury in the rat: effects on lipid metabolism, tissue magnesium and water content. J Neurotrauma 5:105-119

34. Segler-Stahl K, Demediuk P, Castillo R, Watts C, Moscatelli EA 1985 Phospholipids of normal and experimentally injured spinal cord of the miniature pig. Neurochem Res 10:563-569

35. Wei EP, Lamb RG, Kontos HA 1982 Increased phospholipase C activity after experimental brain injury. J Neurosurg 56:695-698

36. Vink R 1989 Phospholipase C activity reduces free magnesium concentration. Biochem Biophys Res Commun 165:913-918

37. Heath DL, Vink R 1998 Blood-free magnesium concentration declines following graded experimental traumatic brain injury. Scand J Clin Lab Invest 58:161-166

38. Hoshino K, Ogawa K, Hishitani T, Kitazawa R 2000 Characteristics of improve NOVA magnesium ion-selective electrode: changes of ionized magnesium values and reference interval in healthy children. Magnes Res 14:203-210

39. Batista A, Corbet R, Tidor S, Castleman E, Laptook A, Sherry AD 2000 Comparison of the distribution of magnesium in plasma determined by size exclusion chromatography and 31P NMR spectroscopy. Magnes Res 23:3-9 